\title{
EFEITO DA QUITOSANA NA EMERGÊNCIA, DESENVOLVIMENTO INICIAL E CARACTERIZAÇÃO BIOQUÍMICA DE PLÂNTULAS DE Acacia mearnsii ${ }^{1}$
}

\author{
Álvaro Rodrigo Freddo², Sérgio Miguel Mazaro³, Eleandro José Brun³ e Américo Wagner Júnior ${ }^{3}$
}

\begin{abstract}
RESUMO - A quitosana é um polímero que vem sendo testado na proteção e indução de resistência em frutos, contra patógenos causadores de podridões. O presente trabalho teve como objetivo principal testar o efeito do tratamento de sementes de Acacia mearnsii com esse produto, bem como seu efeito no desenvolvimento inicial e na caracterização bioquímica das plântulas. Para tanto realizou-se este trabalho na Unepe de Silvicultura e no Laboratório de Fitossanidade da Universidade Tecnológica Federal do Paraná - Câmpus Dois Vizinhos. As sementes de Acacia mearnsii foram tratadas com diferentes concentrações de quitosana $(0 ; 0,25 ; 0,5 ; 1$ e $2 \%$ ) e plantadas em tubetes com o substrato contaminado com o fungo Rhizoctonia solani. Avaliou-se aos 22 dias após a semeadura, a porcentagem de emergência, o índice de velocidade de emergência, a altura das plântulas, o comprimento da radícula, a massa da matéria fresca, além das variáveis bioquímicas dos tecidos foliares, o teor de proteínas totais e de compostos fenólicos e a atividade da enzima fenilalanina amônialiase (FAL). Os resultados obtidos demonstraram que o uso de concentrações de quitosana entre 0,6 e $0,9 \%$ foram mais favoráveis à emergência e ao desenvolvimento das plântulas. Bioquimicamente, a quitosana demonstrou capacidade de alteração do teor de proteínas e da atividade da FAL, enzima a qual, está no ponto de ramificação entre o metabolismo primário e o secundário, indicando a possibilidade de ter havido ativação do sistema de defesa vegetal das plântulas, pelo tratamento das sementes com quitosana.
\end{abstract}

Palavras-chave: Acácia-negra, Rhizoctonia solani e Damping-off.

\section{EFFECT OF CHITOSAN IN EMERGENCY, INITIAL DEVELOPMENT AND BIOCHEMICAL CHARACTERIZATION OF Acacia mearnsii SEEDLINGS}

\begin{abstract}
Chitosan is a polymer that has been tested for production as well the induction of resistance from fruits against pathogens that cause rots. The objective of this work was to test the effect of chitosan treatments upon Acacia mearnsii seeds in relation to initial development and biochemical characterization of seedlings. The present research was carried out in Silviculture Unepe and in the Plant Health Laboratory at the Federal Technological University of Paraná - Campus Dois Vizinhos. Acacia mearnsii seeds were treated with different concentrations of chitosan $(0 ; 0.25 ; 0.5 ; 1$ and 2\%) and grown in tubes with substrate contaminated with Rhizoctonia solani. Twenty two days after sowing, the emergence percentage, the index of germination speed, the seedling height, the radicule length, the fresh weight, and biochemical variables of leaf tissues, the protein content and total phenolic compounds and the activity of the enzyme phenylalanine ammonialyase (PAL) were evaluated. The results showed that concentrations of chitosan between 0.6 and $0.9 \%$ were more effective in promoting germination and seedling development. Biochemically, chitosan demonstrated ability to change the protein content and activity of PAL, an enzyme which is the branching point between primary and secondary metabolism, indicating the possibility of activation of the plant defense system by seed treatment with chitosan.
\end{abstract}

Keywords: Black acacia, Rhizoctonia solani and Damping-off.

\footnotetext{
${ }^{1}$ Recebido em 20.04.2012 aceito para publicação em 04.06.2012

${ }^{2}$ União de Ensino do Sudoeste do Paraná, Microbiologia e Fitopatologia do Curso de Agronomia da UNISEP/DV. E-mail: $<$ alvaro.freddo@hotmail.com>.

${ }^{3}$ Universidade Tecnológica Federal do Paraná, Unidade Sudoeste do Paraná, Dois Vizinhos-Pr. E-mail: <sergio@ utfpr.edu.br> e<eleandro@utfpr.edu.br>e<americo@utfpr.edu.br>.
} 


\section{INTRODUÇÃO}

A acácia-negra (Acacia mearnsii De Wild.) é considerada excelente espécie para florestamento, devido ao seu rápido crescimento e aproveitamento integral da madeira (SANTOS et al., 2001). A madeira desta árvore é utilizada para produção de celulose e papel, aglomerados e energia, sendo a casca utilizada para extração de tanino (CALDEIRA et al., 2004). Esta espécie é plantada principalmente por pequenos produtores do Rio Grande do Sul, visando suprir as empresas de base florestal desse Estado (EMBRAPA, 2003).

Os florestamentos de A. mearnsii são feitos com mudas produzidas em viveiros, que quando produzidas por via seminal podem sofrer tombamento de plântulas ou damping-off.

Diversas espécies de fungos podem destruir as sementes, diminuir a germinação e causar problemas nas plântulas e doenças nas plantas (MARTINELLISENEME et al., 2006). Entre os agentes causais mais comuns de damping off estão os fungos dos gêneros Pythium, Rhizoctonia e Phytophthora (BEDENDO, 2011). O fungo Rhizoctonia solani é anamorfo do Basidiomiceto Thanatephorus (CUBETA; VILGALYS, 1997), sendo considerado parasita primitivo e não especializado, capaz de causar podridões de sementes e tombamento de mudas em várias culturas e em condições ambientais muito amplas (MICHEREFF et al., 2005).

A quitosana é um amino polissacarídeo derivado da desacetilação da quitina, a qual se constitui na maior parte dos exoesqueletos dos insetos, crustáceos e da parede celular dos fungos. Por ser um produto natural, de baixo custo, renovável, abundante e atóxico, tem sido proposto como material potencialmente atraente para usos diversos, inclusive na agricultura (AZEVEDO et al., 2007).

Cia et al. (2007) afirmaram que existem evidências suficientes comprovando a eficiência da quitosana no controle de doenças originárias de infecções quiescentes em frutos. Aplicada em sementes de beterraba e tomate, a quitosana teve eficiência no controle do tombamento de plântulas causadas por Rhizoctonia solani, além de induzir o sistema de defesa da planta, pelo aumento da atividade da enzima fenilalanina ammonia-liase (FAL) (MAZARO et al., 2009). Entretanto, em sementes florestais, principalmente com Acacia mearnsii, são escassos os trabalhos na literatura que relatem o tratamento das sementes com quitosana no controle do tombamento de plântulas.

Dessa forma, este trabalho teve como objetivo principal estudar o efeito do tratamento das sementes de A. mearnsii com diferentes concentrações de quitosana, na indução de resistência ao tombamento e no desenvolvimento inicial das plântulas.

\section{MATERIAL E MÉTODOS}

Esta pesquisa foi realizada nos Laboratórios de Fitossanidade e no Viveiro Florestal da UTFPR Câmpus Dois Vizinhos.

Os tratamentos aplicados envolveram as concentrações de quitosana de $0 ; 0,25,0,5 ;$ e 1,0 e $2,0 \%$. Utilizou-se quitosana pura, obtida em farmácia de manipulação para o trabalho, a qual foi dissolvida em ácido acético $1 \%$, seguindo diluição com água destilada para obter as concentrações testadas. As sementes foram imersas na solução de quitosana e, então, semeadas em tubetes contendo o substrato composto por Plantmax Florestal $^{\circledR}$.

Antes de receber as sementes, o substrato foi previamente esterilizado em autoclave por $60 \mathrm{~min}$ a 120 oC e, então, inoculado com $R$. solani.

Os inóculos de $R$. solani foram preparados a partir de isolados de culturas puras do Laboratório de Fitossanidade e desenvolvidas em placas de Petri ${ }^{\circledR}$ de $9 \mathrm{~cm}$ de diâmetro com tampa, contendo meio BDA. As placas foram mantidas em estufa incubadora tipo B.O.D. a $23{ }^{\circ} \mathrm{C}$ e fotoperíodo de $12 \mathrm{~h}$. Discos dessa cultura pura foram inoculados em sementes de sorgo previamente autoclavadas, sendo mantidos em incubadora B.O.D. Essas sementes de sorgo contaminadas com $R$. solani foram utilizadas como veículo contaminante ao substrato esterilizado, na proporção de $10 \mathrm{~g} \cdot \mathrm{kg}^{-1}$. O inóculo foi incorporado ao substrato três dias antes de receber as sementes.

Tubetes de polipropileno com capacidade para $50 \mathrm{~cm}^{3}$ receberam o substrato contaminado e foram colocados em estufa no viveiro florestal. Cada repetição foi constituída por 25 tubetes, em que cada um recebeu três sementes tratadas ou não com quitosana. 
As sementes utilizadas, oriundas de um pomar de sementes do Município de Montenegro, RS, tiveram sua dormência tegumentar quebrada por meio do método descrito por Martins-Corder et al. (1999), através de imersão em água quente na temperatura de $80^{\circ} \mathrm{C}$ por $5 \mathrm{~min}$.

A irrigação na estufa do viveiro florestal foi realizada através de aspersão, sendo feitas avaliações diárias da umidade relativa e da temperatura do ar com o auxílio de aparelho termo-higrômetro. A umidade relativa do ar para o experimento ficou em 58,1\%, com desviopadrão de $18 \%$, enquanto a temperatura ficou em média $29,6^{\circ} \mathrm{C}$, com desvio-padrão de $4,3^{\circ} \mathrm{C}$. Essas condições, de alta umidade e temperatura, de acordo com Alfenas et al. (2009), são favoráveis aos fungos causadores de tombamento de mudas.

O experimento foi conduzido até 22 dias após a semeadura, e as primeiras plântulas de $A$. mearnsii começaram a emergir em sete dias.

As variáveis analisadas neste experimento foram: índice de velocidade de emergência (IVE), emergência (\%), tombamento de pós-emergência (\%), comprimento do caulículo e da radícula e massa de matéria fresca das plântulas.

O índice de velocidade de emergência (IVE) foi calculado até o oitavo dia após o início da emergência das plântulas, ou seja, 15 dia após a semeadura, quando a maior parte das plântulas havia emergido. O IVE foi calculado segundo Popinigs (1977), descrito pela fórmula: IVE $=\mathrm{N}_{1} / \mathrm{D}_{1}+\mathrm{N}_{2} / \mathrm{D}_{2}+\ldots+\mathrm{N}_{\mathrm{n}} / \mathrm{D}_{\mathrm{n}}$, em que $\mathrm{N}$ é igual ao número de plântulas emergidas no dia (1; 2; até n) e D o número de dias após a semeadura.

A porcentagem de emergência das plântulas foi avaliada ao término do experimento, calculando-se o stand final de cada unidade experimental.

O percentual de tombamento de pós-emergência das plântulas foi observado diariamente e calculado com base no número de plantas emergentes por parcela.

O comprimento, em centímetros, do caulículo e da radícula foi avaliado ao término do experimento, com utilização de régua graduada.

A produção de massa de matéria fresca total (parte aérea e raízes) das plântulas foi avaliada ao término do experimento. As raízes foram lavadas e as plântulas, pesadas em balança de precisão, sendo esta variável obtida por plântula.
Para cada variável bioquímica, coletaram-se três amostras de plantas por tratamento. A amostra constituiu-se de $0,5 \mathrm{~g}$, mesclada entre todas as partes do vegetal (folhas, talo e raízes), as quais foram imediatamente após a coleta, enroladas em papel-alumínio e congeladas em "freezer" a -20 ${ }^{\circ} \mathrm{C}$ até as avaliações.

Determinaram-se as variáveis bioquímicas: teor de proteínas totais, atividade da fenilalanina amônialiase (FAL) e teor de compostos fenólicos dos tecidos vegetais.

Para avaliação da concentração de proteínas totais, utilizou-se a adaptação do método descrito por Bradford (1976). A determinação da atividade da fenilalanina amônia-liase (FAL) foi determinada com base na diferença de absorbância resultante da conversão da fenilalanina em ácido trans-cinâmico (HYODO et al., 1978) e em método de leitura descrito por Rodrigues et al. (2006).

A quantificação dos compostos fenólicos totais foi realizada em duas etapas, seguindo-se o método adaptado de Bieleski e Turner (1966) para extração e quantificação através da curva- padrão utilizando tirosina (JENNINGS, 1981).

Os dados das variáveis foram submetidos à análise estatística, com o auxílio do software ASSISTAT 7.6 BETA.

Primeiramente, testou-se a normalidade dos dados por meio do Teste de Liliefors e de homogeneidade de variâncias pelo teste de Bartlett. Os dados coletados em porcentagem como a variável porcentagem de emergência não atenderam ao teste de normalidade, sendo, assim, transformados em arcosseno $\mathrm{V}(\mathrm{x} / 100)$.

Os dados transformados e não transformados foram submetidos à análise de variância a $5 \%$ de probabilidade de erro.

Nas variáveis em que houve efeito significativo para os tratamentos, utilizou-se como teste complementar a análise de regressão, determinando, assim, modelos matemáticos para explicar o comportamento com as concentrações de quitosana aplicadas.

\section{RESULTADOS}

De acordo com a análise de variância da porcentagem de emergência das plântulas de A. mearnsii e também do IVE (índice de velocidade de emergência), não houve

Revista Árvore, Viçosa-MG, v.36, n.6, p.1039-1045, 2012 
efeito significativo das concentrações de quitosana aplicadas às sementes. A porcentagem de emergência ficou na média de $41,7 \%$ em todo o experimento, e o IVE médio foi de 2,4. Contudo, o tratamento das sementes de A. mearnsii com quitosana teve influência significativa sobre a incidência de tombamento das plântulas, mostrando a menor média (16,98\%) com o uso de $0,79 \%$ de quitosana. Entretanto, na utilização de concentrações acima de 1,58\% o damping-off foi maior que no tratamento-testemunha (Figura 1).

Com relação à altura das plântulas e comprimento da radícula de $A$. mearnsii, verificou-se efeito significativo da aplicação de quitosana nas sementes (Figuras 2 e 3). Observou-se em ambas (Figuras 2 e 3 ) que a equação que melhor se ajustou para explicar a relação entre o tratamento das sementes de $A$. mearnsii para altura das plântulas e comprimento da radícula, aos 15 dias após a emergência, foi a polinomial quadrática

A maior altura de plântulas de A. mearnsii $(2,28 \mathrm{~cm})$ ocorreu com o uso de $0,88 \%$ de quitosana nas sementes (Figura 2), já para o comprimento da radícula se obteve a maior média $(11,60 \mathrm{~cm})$, com o uso de $0,63 \%$ de quitosana nas sementes (Figura 3).

A massa de matéria fresca das plântulas de $A$. mearnsii 15 dias após a emergência não foi influenciada

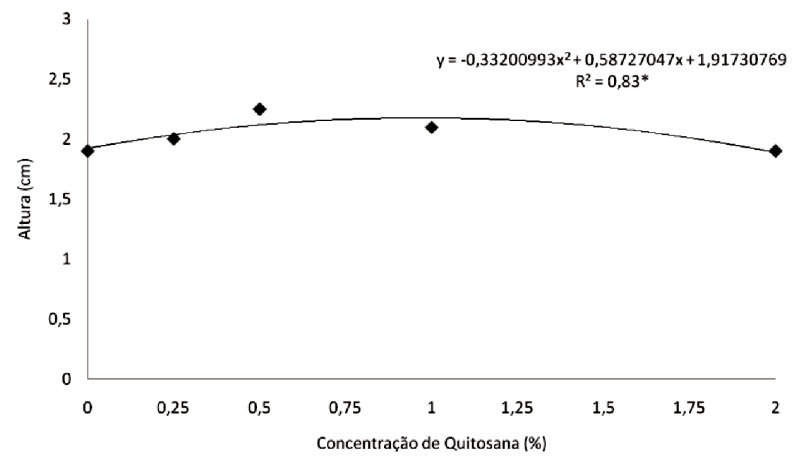

Figura 1 - Incidência de damping-off em plântulas de A. mearnsii oriundas de sementes tratadas com cinco concentrações de quitosana, UTFPR, Câmpus Dois Vizinhos, PR. *Significativo ao nível de $5 \%$ de probabilidade. Dados transformados em arc sen $\mathrm{V} / 100$.

Figure 1 -Damping-off incidence in A. mearnsii seedlings from seeds treated with five concentrations of chitosan, UTFPR, Campus Dois Vizinhos, PR. *Significant at the level of 5\%. Data transformed into $\operatorname{arc} \sin \mathrm{V}(x / 100)$.

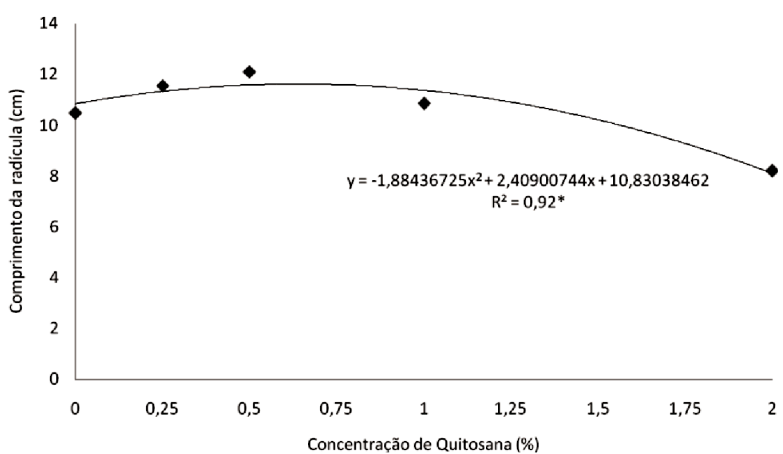

Figura 2 - Altura de plântulas de A. mearnsii oriundas de sementes tratadas com cinco concentrações de quitosana, aos quinze dias após a emergência, UTFPR, Câmpus Dois Vizinhos, PR. *Significativo ao nível de $5 \%$ de probabilidade.

Figure 2 - Height of A. mearnsii seedlings from seeds treated with Five concentrations of chitosan, the fifteenth day after the emergence, UTFPR, Campus Dois Vizinhos, PR. *Significant at $5 \%$ level.

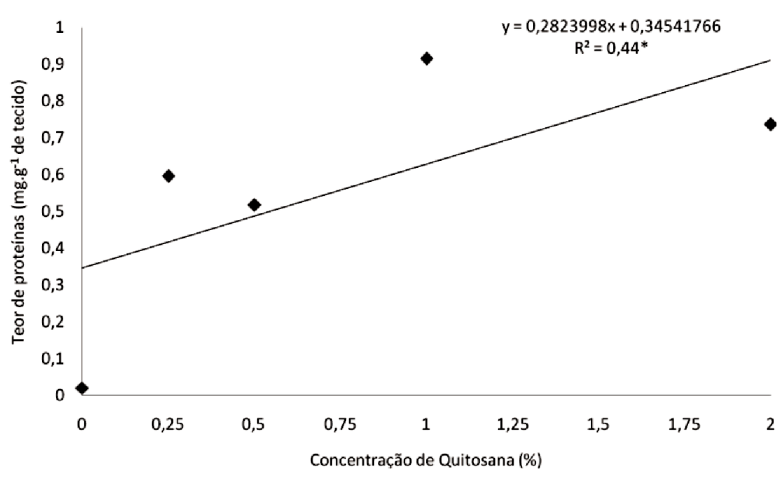

Figura 3 -Comprimento da radícula de plântulas de A. mearnsii oriundas de sementes tratadas com cinco concentrações de quitosana, aos quinze dias após a emergência, UTFPR, Câmpus Dois Vizinhos, PR. *Significativo ao nível de $5 \%$ de probabilidade.

Figure 3 - Height of A. mearnsii seedlings from seeds treated with five concentrations of chitosan, on the fifteenth day after the emergence, UTFPR, Campus Dois Vizinhos, PR. *Significant at the level of $5 \%$.

significativamente pelas concentrações de quitosana aplicadas nas sementes.

O teor de proteínas dos tecidos vegetais de $A$. mearnsii foi influenciado pelas concentrações de quitosana aplicadas às sementes (Figura 4), obtendose comportamento linear crescente com o aumento da concentração do agente indutor.

Revista Árvore, Viçosa-MG, v.36, n.6, p.1039-1045, 2012 
Para o teor da enzima fenilalanina amônia-liase (FAL), houve influência significativa do uso de quitosana nas sementes de $A$. mearnsii, obtendo-se comportamento linear crescente com o aumento da concentração utilizada (Figura 5).

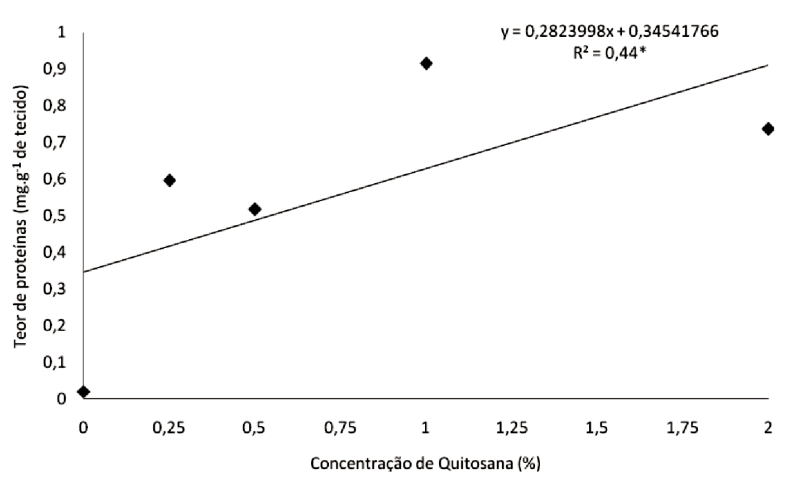

Figura 4 - Teor de proteínas $\left(\mathrm{mg} \mathrm{g}^{-1}\right.$ de tecido) de plântulas de A. mearnsii, oriundas de sementes tratadas com cinco concentrações de quitosana, aos quinze dias após a emergência, UTFPR, Câmpus Dois Vizinhos, PR. *Significativo ao nível de $5 \%$ de probabilidade.

Figure 4-Protein content ( $m g g^{-1}$ of tissue) of A. mearnsii seedlings from seeds treated with five concentrations of chitosan, on the fifteenth day after emergence, UTFPR, Campus Dois Vizinhos, PR. *Significant at the level of $5 \%$.

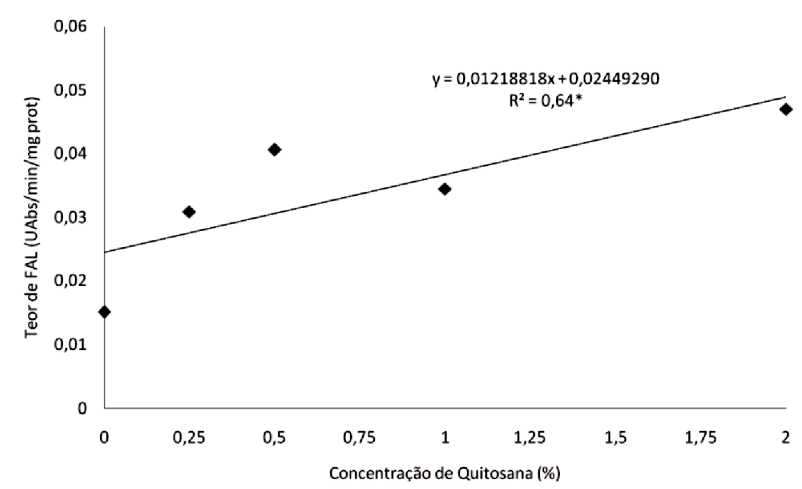

Figura 5 - Teor de FAL (fenialanina amônia-liase) de plântulas A. mearnsii com as sementes tratadas com diferentes concentrações de quitosana, aos quinze dias após a emergência, UTFPR, Câmpus Dois Vizinhos, PR. *Significativo ao nível de $5 \%$ de probabilidade.

Figure 5 - PAL (phenylalanine ammonia-lyase) content of A. mearnsii seedlings from seeds treated with five concentrations of chitosan, on the fifteenth day after emergence, UTFPR, Câmpus Dois Vizinhos, $P R$. *Significant at the level of $5 \%$ level.
Entretanto, o teor dos compostos fenólicos totais não foi alterado pela utilização do tratamento das sementes com quitosana, pois na análise de variância não houve diferença estatística entre os tratamentos testados.

\section{DISCUSSÃO}

A porcentagem de emergência obtida neste experimento ( $41 \%$ ) equivale a um valor bem abaixo do obtido por Roversi et al. (2002), o qual foi de 81,0\% com imersão em água quente a $90^{\circ} \mathrm{C}$ e também abaixo de $84,0 \%$, que é o resultado obtido por Martins-Corder et al. (1999), com imersão em água quente a $80^{\circ} \mathrm{C}$.

A hipótese mais provável da baixa emergência neste experimento é a de que a inoculação do substrato com o micélio de $R$. solani atuou negativamente no índice de emergência do experimento, causando tombamento de pré-emergência nas plântulas. Martins-Corder e Borges Júnior (1999), estudando a desinfestação e quebra de dormência de $A$. mearnsii, explicaram que a principal causa da ausência de germinação em sementes que tiveram sua dormência quebrada foi a presença de fungos e bactérias nos propágulos.

Goulart (2002), estudando o efeito de diferentes fungicidas no tratamento de sementes de algodoeiro para controle de tombamento de plântulas causado por $R$. solani, encontrou valores de damping-off superiores aos encontrados neste trabalho, utilizando as misturas de fungicidas: Carboxin+thiram+benomyl (30,2\% de tombamento) e Thiram+thiabendazole +difenoconazole $(46,9 \%)$.

Observou-se que em concentrações maiores que $1,58 \%$ a incidência de damping-off foi maior que no tratamento-testemunha, o que pode ser explicado pelo fato de nessas concentrações ter provavelmente ocorrido fitotoxidade às plântulas, o que diminuiu o crescimento radicular e aumentou o tombamento das plântulas (Figuras 1 e 3). Bedendo (2011) citou que plântulas com menor vigor e menor crescimento radicular são mais suscetíveis ao ataque de patógenos.

Campos et al. (2009) estudaram o efeito do tratamento químico de sementes de mamão visando ao controle de tombamento de $R$. solani, em que observaram que os tratamentos que reduziram ou atrasaram a emergência foram os que apresentaram maior percentual de plântulas mortas em pós-emergência. Esses autores explicaram 
que o motivo de maior percentual de damping-offé o fato de que os tratamentos promoveram retardo ao escape da doença e da disponibilidade de tecido suscetível ao patógeno.

A maior média de altura deste experimento foi obtida na concentração de $0,88 \%$ de quitosana (Figura 2), enquanto Mazaro et al. (2009) encontraram maior altura de plântulas de tomateiro, quando as sementes foram tratadas com concentrações acima de $2 \%$ de quitosana.

Mazaro et al. (2009) observaram que os tratamentos nas sementes de beterraba e tomate utilizando as concentrações entre $2 \%$ e $4 \%$ foram as que proporcionaram maior crescimento radicular, principalmente por estarem relacionados com a redução da incidência de tombamento das plântulas. Neste trabalho, também houve correlação semelhante, pois a concentração em que houve o menor percentual de tombamento foi a de 0,79\% de quitosana (Figura 1), e o comprimento radicular foi maior na concentração de $0,63 \%$ de quitosana (Figura 3), ou seja, em faixas muito próximas.

Bedendo (2011) afirmou que a promoção do rápido desenvolvimento da plântula é uma medida de controle do damping-off, pois possibilita maior absorção de água e nutrientes, além da maturação dos tecidos jovens, tornando-a mais resistente aos patógenos, o que é observado neste trabalho, em que plantas com maior altura e comprimento da radícula estão na faixa onde houve menor incidência da doença. Entretanto, Mazaro et al. (2009) encontraram influência significativa na utilização do polímero, com ganho de massa de matéria fresca em beterraba e tomate, sendo no último, quando as sementes foram tratadas com concentrações acima de $2 \%$ de quitosana, o resultado maior.

O trabalho de Mazaro et al. (2009) corrobora os resultados obtidos de A. mearnsii, uma vez que esses autores observaram que o uso da quitosana em sementes de beterraba aumentou o teor proteico das plântulas.

Mazaro et al. (2009) verificaram aumento da atividade da FAL em plântulas de beterraba e tomate com as sementes tratadas com quitosana, corroborando os resultados obtidos neste trabalho, em que o tratamento das sementes com esse produto aumentou a atividade dessa enzima.
Os maiores teores proteicos das plântulas podem indicar que houve maior desenvolvimento delas pela ação da quitosana, entretanto se pode aceitar a hipótese de indução de resistência, pois, de acordo com Pascholatti (2011), proteínas-RP (proteínas relacionadas à patogênese) podem ser produzidas por tecidos em respostas à ação de agentes elicitores endógenos e exógenos, o que corrobora os resultados do experimento, indicando que a quitosana pode ser indutor de $A$. mearnsii.

Entretanto, a hipótese de indução de resistência não pode ser elucidada, pois o teor de fenóis totais não foi afetado significativamente pela aplicação de quitosana nas sementes de A. mearnsii. De acordo com Taiz e Zeiger (2004), a FAL está situada em um ponto de ramificação entre o metabolismo primário e o secundário, e a reação que ela catalisa regula a formação de muitos compostos fenólicos.

\section{CONCLUSÕES}

As concentrações de quitosana entre $0,6 \%$ e $0,9 \%$ são recomendadas para aplicação nas sementes de Acacia mearnsii de forma a reduzir o tombamento e acelerar o desenvolvimento inicial das plântulas..

A quitosana demonstra capacidade de alteração do teor de proteínas dos tecidos vegetais da Acacia mearnsii e da capacidade de ativação da enzima FAL.

\section{REFERÊNCIAS}

AlfEnAS, A. C. et al. Clonagem e doenças do eucalipto. Viçosa, MG: Universidade Federal de Viçosa, 2009. 500p.

AZEVEDO, V. et al. Quitina e quitosana: aplicações como biomateriais. Revista Eletrônica de Materiais e Processos, v.2, n.3, p.27-34, 2007.

BEDENDO, I. P. DAMPING-OFF. In: AMORIM, L.; REZENDE, J. A. M.; BERGAMIM FILHO, A. (Ed.). Manual de fitopatologia 1: princípios e conceitos. São Paulo: Agronômica Ceres, 2011. p.435-441.

BIELESKI, R. L.; TURNER, N. A. Separation and estimation of amino acids in crude plant extracts by thin-layer electrophoresis and chromatography. Analytical Biochemistry, v.17, n.2, p.278-293, 1966. 
BRADFORD, M. M. A rapid and sensitive method for the quantification of microgram quantities of protein utilizing the principle of protein-dye binding. Analytical Biochemistry, v.72, n.1-2, p.248-254, 1976 .

CALDEIRA, M. V. W.; RONDON NETO, R. M.; SCHUMACHER, M. V. Eficiência do uso de micronutrients e sódio em três procedências de acacia-negra (Acacia mearnsii De Wild.).

Revista Árvore, v.28, n.1, p.39-47, 2004.

CAMPOS, S. C. et al. Tratamento químico de sementes de mamão visando ao controle de Rhizoctonia solani. Tropical Plant Pathology, v.34, n.3, p.192-197, 2009.

CIA, P.; PASCHOLATI, S. F.; BENATO, E. A. Indução de resistência no manejo de doenças pós-colheita. In: RODRIGUES, F. Á.; ROMEIRO, R. S. (Ed.). Indução de resistência em plantas a patógenos. Viçosa, MG: Universidade Federal de Viçosa, 2007. p.245-280.

CUBETA, M. A.; VILGALYS, R. Population biology of the Rhizoctonia solani complex. Phytopathology, v.87, n.4, p.480-484, 1997.

EMPRESA BRASILEIRA DE PESQUISA AGROPECUÁRIA - EMBRAPA. Cultivo da acacia-negra. Disponível: http:// www.sistemasdeproducao.cnptia.embrapa.br. Acesso em: 15 out. 2011.

GOULART, A. C. P. Efeito do tratamento de sementes de algodão com fungicidas no controle do tombamento de plântulas causado por Rhizoctonia solani. Fitopatologia Brasileira, v.27, n.4, p.399-402, 2002.

HYODO, H.; KURODA, H.; YANG, S. F. Induction of phenylalanine ammonia-lyase and increase in phenolics in lettuce leaves in relation to the development of russet spoting caused by ethylene. Plant Physiology, v.62, n.1, p.31-35, 1978.

JENNINGS, A. C. The determination al dihydroxy phenolic compounds in extracts of plant tissues. Analytical Biochemistry, v.118, n.2, p.396-398, 1981.

MARTINELLI-SENEME, A. et al. Germinação e sanidade de sementes de Bauhinia variegata. Revista Árvore, v.30, n.5, p.719-724, 2006.
MARTINS-CORDER, M. P.; BORGES JÚNIOR, N. Desinfestação e quebra de dormência em sementes de Acacia mearnssii De Willd. Ciência Florestal, v.9, n.2, p.1-7, 1999.

MARTINS-CORDER, M. P.; BORGES, R. Z.; BORGES JÚNIOR, N. Fotoperiodismo e quebra de dormência em sementes de acácia-negra (Acacia mearnssii De Willd.). Ciência Florestal, v.9, n.1, p.71-77, 1999.

MAZARO, S. M. et al. Controle do tombamento de plântulas de beterraba e tomate pelo tratamento das sementes com quitosana. Pesquisa Agropecuária Brasileira, v.44, n.11, p.1424-1430, 2009.

MICHEREFF, S. J. et al. Importância dos patógenos e das doenças radiculares em solos tropicais. In: MICHEREFF, S. J.; ANDRADE, D. E. G. T.; MENEZES, M. (Ed.). Ecologia e manejo de patógenos radiculares em solos tropicais. Recife: Universidade Federal Rural de Pernanbuco, 2005. p. 1-18.

PASCHOLATI, S. F. Fisiologia do parasitismo: como as plantas se defendem dos patógenos. In: BERGAMIN FILHO, A.; KIMATI, H.; AMORIM, L. (Ed.). Manual de fitopatologia 1: princípios e conceitos. São Paulo: Agronômica Ceres, 2011.p.593-636.

POPINIGS, F. Fisiologia de sementes. Brasília: AGIPLAN, 1977. 329p.

RODRIGUES, A. A. C.; BEZERRA NETO, E.; COELHO, R. S. B. Indução de resistência a Fusarium oxysporum f. sp. tracheiphilum em caupi: eficiência de indutores abióticos e atividade enzimática elicitada. Fitopatologia Brasileira, v.31, n.5, p.492-499, 2006.

ROVERSI, T. et al. Superação da dormência em sementes de acácia-negra ( $A$. mearnssii Willd.). Revista Brasileira de Agrociência, v.8, n.2, p.161-163, 2002.

SANTOS, A. F. et al. O complexo gomose da acacia-negra. Colombo: Embrapa - CNPF, 2001. 8p. (Circular Técnica 44)

TAIZ, L.; ZEIGER, E. Fisiologia vegetal. Tradução: SANTAREM et al. Porto Alegre: Artmed, 2004, 719p.

Revista Árvore, Viçosa-MG, v.36, n.6, p.1039-1045, 2012 
